\title{
Transient Ischemic Attack versus Transient Ischemic Attack Mimics: Frequency, Clinical Characteristics and Outcome
}

\author{
Margareth Amort ${ }^{\mathrm{a}}$ Felix Fluri $^{\mathrm{a}} \quad$ Juliane Schäfer ${ }^{\mathrm{b}}$ Florian Weisskopf ${ }^{\mathrm{a}}$ \\ Mira Katan $^{\mathrm{a}}$ Annika Burow ${ }^{\mathrm{a}}$ Heiner C. Bucher ${ }^{\mathrm{b}}$ Leo H. Bonati ${ }^{\mathrm{a}}$ \\ Philippe A. Lyrer ${ }^{a}$ Stefan T. Engelter ${ }^{a}$ \\ a Stroke Unit and Department of Neurology, and ${ }^{\mathrm{b}}$ Basel Institute for Clinical Epidemiology and Biostatistics, \\ University Hospital Basel, Basel, Switzerland
}

\section{Key Words}

Transient ischemic attack $\cdot$ Mimics $\cdot$ Emergency medical services $\cdot$ Clinical symptoms $\cdot$ Outcome

\begin{abstract}
Background: There is insufficient evidence regarding which clinical features are best suited to distinguish between transient ischemic attack (TIA) and disorders mimicking TIA (TIA mimics). Methods: We compared the frequency, clinical characteristics and outcome of patients with TIA and TIA mimics in a prospective, single-center emergency department cohort over 2 years. Results: Of 303 patients, 248 (81.8\%) had a TIA and 55 (18.2\%) had TIA mimics. Epileptic seizures $(26 / 55 ; 43.7 \%)$ and migraine attacks $(13 / 55 ; 23.6 \%)$ were the most common TIA mimics. In patients presenting with unilateral paresis, TIA mimics were less likely than in patients without unilateral paresis [odds ratio (OR) $0.35,95 \%$ confidence interval (Cl) 0.17-0.68]. Memory loss (OR 9.17, $95 \% \mathrm{Cl} 2.89-32.50$ ), headache (OR 3.71, 95\% Cl 1.07-12.78) and blurred vision (OR $2.48,95 \% \mathrm{Cl} 0.90-6.59)$ increased the odds of TIA mimics. Once these clinical features were taken into account, neither aphasia, dysarthria, sensory loss, blood
\end{abstract}

pressure values nor the duration of symptoms were found to improve explanation of the underlying status. At 3 months, stroke, recurrent TIA and myocardial infarction were absent in patients with TIA mimics but occurred in $13(5.2 \%), 20$ (8.1\%) and 3 (1.2\%) TIA patients, respectively. Conclusions: About 1 in every 5 patients with suspected TIA had a TIA mimic. Paresis suggested TIA, while other clinical variables used in risk assessment scores after TIA were not shown to distinguish between the two entities. Patients with TIA mimics had a better short-term prognosis.

Copyright $\odot 2011$ S. Karger AG, Basel

\section{Introduction}

Patients suffering from a transient ischemic attack (TIA) have a high risk of stroke within the first 3 months, ranging from $9 \%$ up to $20 \%$ at 90 days [1-9]. The risk of stroke is particularly high in the first few days, underlin-

\section{M.A. and F.F. contributed equally to this work.}

\section{KARGER}

Fax +41613061234 E-Mail karger@karger.ch www.karger.com
(C) 2011 S. Karger AG, Basel

1015-9770/11/0321-0057\$38.00/0

Accessible online at:

www.karger.com/ced
Margareth Amort, MD

Department of Neurology and Stroke Unit

University Hospital Basel, Petersgraben 4

CH-4031 Basel (Switzerland)

Tel. +41 61265 2525, E-Mail mamort@uhbs.ch 
ing the need for urgent evaluation and treatment of patients with TIA [10]. However, there are patients with transient focal neurological symptoms which are not attributable to a focal cerebral ischemia [11]. Such conditions may imitate a TIA and can therefore be labeled TIA mimics, in analogy to conditions that imitate a stroke and have been labeled stroke mimics $[12,13]$. The rate of TIA mimics ranges from 10 to $48.5 \%$ [14-17] depending on the setting. Diagnostic procedures and therapeutic measures differ between patients with TIA and patients with TIA mimics. Therefore, it would be useful to identify clinical features which aid in distinguishing between the two entities. With these considerations in mind, we compared the frequency, clinical characteristics and prognosis of patients with TIA and patients with TIA mimics presenting to an experienced stroke center.

\section{Methods}

\section{Setting and Study Objectives}

The Basel Stroke Unit program includes a prospective registry and defines management pathways. In summer 2006, we designed a prospective, single-center TIA study with the following objectives: (1) to evaluate the quality of the management of TIA patients in our hospital [18], (2) to explore which features are best suited to distinguish between TIA and disorders mimicking TIA and (3) to test whether a refinement of the age, blood pressure, clinical symptoms and duration of symptoms (ABCD) score may increase the predictability of subsequent stroke or recurrent TIA.

Over a period of 24 months (from 5 November 2006 to 4 November 2008), all consecutive patients admitted to the emergency department (EMD) with suspected TIA as assessed by the EMD physician were analyzed.

Due to lack of a universally agreed definition of TIA mimics $[11,14,15]$, we distinguished the two entities by adapting the criteria used to distinguish stroke from stroke mimics as follows. Adhering to the classical definition, TIA was defined as an acute loss (i.e. within seconds or less) of focal cerebral or ocular function with symptoms lasting $<24 \mathrm{~h}$ of presumed ischemic origin $[11,19]$. All patients with an underlying nonischemic disorder were classified as having TIA mimics [11]. The clinical diagnosis of TIA is subject to interobserver disagreement [20, 21]. In order to minimize the risk of misclassification, two stroke neurologists blinded to the final outcome assessed case report forms and clinical data by chart review and reclassified the patients as TIA or TIA mimics by consensus, adopting a similar approach to that used for distinguishing stroke from mimics [12]. The diagnosis of TIA or TIA mimics was based on clinical criteria alone; the results of diagnostic investigations such as neuroimaging or EEG did not play a role in this process.

Data were collected on a standardized case report form that was prospectively applied in all patients. The following variables were assessed: demographic variables (age, sex), body mass index, details of clinical symptoms, vascular risk factors based on criteria used in a previous study [22], ABCD [23] and age, blood pres- sure, clinical symptoms, duration of symptoms and diabetes (ABCD2) scores [15], vital signs and findings of the ancillary investigations detailed below. We collected information on 11 clinical symptoms: unilateral paresis (i.e. one-sided weakness of the face, arm and/or leg), unilateral sensory loss (i.e. one-sided numbness or altered sensation including pins and needles in the face, arm and/or leg), aphasia (i.e. inability to use or understand language, either spoken or written), dysarthria (i.e. slurred speech), transient monocular blindness (i.e. partial or total blindness of one eye), hemianopia (i.e. blindness to one side), diplopia (i.e. double vision), vertigo (i.e. a sensation of a whirling motion, either of the patient or of the environment), blurred vision, memory loss and headache. Features present in only a few patients e.g. paraparesis $(n=7)$, tetraparesis $(n=4)$, march of symptoms $(n=5)$ and limb movement $(n=3)$, were excluded from the analysis in analogy to a recent study on stroke mimics [12].

Appropriate measures of stroke prevention were initiated immediately based on current guidelines [19]. This included starting antithrombotic agents, statins, antihypertensive therapy and lifestyle counseling, as well as specific interventions tailored to the underlying etiology. Antiplatelet therapy with acetylsalicylic acid (ASA) as the first-line agent was used in patients with TIA due to large-artery atherosclerosis, small-artery occlusion or of undetermined etiology; clopidogrel was used in patients with contraindications for ASA or for those who were on ASA at the time of their index TIA. Anticoagulation with phenprocoumon was used for cardioembolic TIAs.

Patients with 4 or fewer points on the ABCD score [23], no acute ischemic lesions on diffusion-weighted MRI of the brain, less than $50 \%$ stenosis of the large arteries and no high-risk abnormality on electrocardiogram (ECG) were managed as outpatients, whereas patients presenting at least one of these criteria were hospitalized.

At 3 months, patients were followed up clinically at outpatient visits by a stroke neurologist. The following outcome events were assessed: stroke, recurrent TIA and myocardial infarction (MI). Stroke was defined as an acute deficit of focal neurological function with symptoms lasting more than $24 \mathrm{~h}$, resulting from an intracranial vascular disturbance (ischemia or hemorrhage). The diagnosis of MI required 2 out of the following 3 criteria: a history of prolonged chest discomfort, the development of specific abnormalities on a standard 12-lead ECG and specific cardiac enzymes elevated more than twice the upper limit of normal. All outcome events were adjudicated by a senior stroke neurologist.

If patients did not accept our invitation for a clinical follow-up visit, their vital status was investigated. A standardized telephone interview was carried out in those who declined follow-up visits to assess any symptoms of the above-defined vascular outcome events. If this interview showed signs suggestive of a vascular event, an urgent clinical visit with further investigations was scheduled in order to evaluate the occurrence of an outcome event.

\section{Statistical Analysis}

We used descriptive statistics with absolute and relative frequencies for categorical variables and median and interquartile range for continuous variables to study differences in the distribution of patient characteristics at baseline between patients with TIA and TIA mimics. The p values calculated using Fisher's exact test and the Mann-Whitney test, respectively, are also shown. 
Table 1. Patient baseline characteristics

\begin{tabular}{lcccc}
\hline & $\begin{array}{l}\text { All patients } \\
(\mathrm{n}=303)\end{array}$ & $\begin{array}{l}\text { TIA mimics } \\
(\mathrm{n}=55 ; 18.2 \%)\end{array}$ & $\begin{array}{l}\text { TIA } \\
(\mathrm{n}=248 ; 81.8 \%)\end{array}$ & p value \\
\hline $\begin{array}{l}\text { Age, years } \\
\text { Males }\end{array}$ & $71(61.0-79.0)$ & $66(56.0-76.5)$ & $72(62.0-79.0)$ & $0.050^{2}$ \\
Vascular risk factors & $178(58.8)$ & $29(52.7)$ & $149(60.1)$ & $0.364^{3}$ \\
$\quad$ Hypertension & $211(69.6)$ & $36(65.5)$ & $175(70.6)$ & $0.517^{3}$ \\
$\quad$ Coronary heart disease & $53(17.5)$ & $6(10.9)$ & $47(18.9)$ & $0.175^{3}$ \\
$\quad$ Current smoking & $60(19.8)$ & $7(12.7)$ & $53(21.4)$ & $0.190^{3}$ \\
$\quad$ Diabetes mellitus & $48(15.8)$ & $7(12.7)$ & $41(16.5)$ & $0.547^{3}$ \\
$\quad$ Hypercholesterolemia & $115(38.0)$ & $19(34.5)$ & $96(38.7)$ & $0.646^{3}$ \\
$\quad$ Family history of stroke & $70(23.1)$ & $16(29.1)$ & $54(21.8)$ & $0.288^{3}$ \\
$\quad$ Peripheral arterial disease & $24(7.9)$ & $2(3.6)$ & $22(8.9)$ & $0.272^{3}$ \\
$\quad$ Atrial fibrillation & $38(12.5)$ & $1(1.8)$ & $37(14.9)$ & $0.006^{3}$ \\
BMI ${ }^{1}$ & $25.3(23.3-27.9)$ & $25.7(23.5-28.3)$ & $25.2(23.3-27.8)$ & $0.402^{2}$ \\
ABCD score & $4.0(3.0-5.0)$ & $4.0(3.0-5.0)$ & $4.0(3.0-5.0)$ & $0.027^{2}$ \\
ABCD2 score & $4.0(3.0-5.0)$ & $4.0(3.0-5.0)$ & $4.0(3.0-5.0)$ & $0.018^{2}$ \\
\hline
\end{tabular}

Values represent medians (interquartile ranges) or numbers (percentages). BMI = Body mass index; $\mathrm{ABCD}=$ prognostic score developed to determine stroke risk after TIA [15].

${ }^{1}$ Based on $240 / 303$ patients. ${ }^{2}$ Mann-Whitney test. ${ }^{3}$ Fisher's exact test.

To assess whether the continuous variables considered for predictive modeling have strictly linear effects, we fitted univariate additive logistic regression models using penalized regression splines for the smoothers [24].

We included 15 prespecified candidate predictors (i.e. 11 symptoms plus age, symptom duration, diastolic and systolic blood pressure) in univariate linear logistic regression models, where the effect of variables which were present exclusively in one group (e.g. TIA) and were absent in the other group was evaluated with exact inference [25-28].

The primary analysis was performed with a classical multiple linear logistic regression model chosen in a stepwise algorithm via the Akaike information criterion [29]. Variables suffering from small-data problems were not included in this model, but were studied later in a post hoc multiple regression analysis by means of exact inference.

Predictive performance of this model was evaluated with the Brier score [30] and the area under the receiver operating characteristic curve (AUC). A useful prediction rule should have a Brier score below 0.25 , indicating the worst case scenario for decision making. Resubstitution comparisons are likely to be too optimistic. Therefore, we also used bootstrap cross-validation with $B=25$ subsamples and applied the $0.632+$ method [31]. For a fair comparison model selection was performed in each bootstrap sample.

Analyses were performed using the $\mathrm{R}$ system for statistical computing [32].

Ethics

The local ethics committee approved the study.

\section{Results}

\section{Study Population}

All 303 patients admitted to the EMD with suspected TIA during the study enrolment period were included in the present analysis. All study patients had a clinical neurological exam on admission; in addition, the following diagnostic tests were performed in some patients (number of tests; percentage in TIA patients; percentage in patients with TIA mimics). Computed tomography (CT) with CT angiography ( $\mathrm{n}=194 ; 62.9 \% ; 69.1 \%)$, MRI, including diffusion-weighted imaging and MR angiography $(\mathrm{n}=251 ; 81.9 \% ; 87.3 \%)$, transthoracic echocardiography ( $\mathrm{n}=183 ; 66.1 \%$; 34.5\%), transesophageal echocardiography $(\mathrm{n}=22 ; 7.3 \% ; 7.3 \%)$, neurosonology $(\mathrm{n}=277$; $94.0 \% ; 80.0 \%)$, ECG ( $\mathrm{n}=303 ; 100.0 \% ; 100.0 \%)$, 24-hour ECG $(\mathrm{n}=126 ; 45.2 \% ; 25.5 \%)$ and EEG $(\mathrm{n}=48 ; 10.9 \%$; $38.2 \%)$. Patient characteristics at baseline are shown in table 1.

Fifty-five patients (18.2\%) were classified as having TIA mimics. Epileptic seizures (43.7\%) and migraine attacks (23.6\%) were the most common diagnoses among patients with TIA mimics (table 2).

Atrial fibrillation was more common in patients with TIA ( $\mathrm{n}=37 ; 14.9 \%)$ than in patients with TIA mimics $(\mathrm{n}=1 ; 1.8 \% ; \mathrm{p}=0.006)$. Gender, body mass index and the frequency of other vascular risk factors were balanced be- 
Table 2. Causes of TIA mimics

\begin{tabular}{lc}
\hline Diagnosis of TIA mimics $(\mathrm{n}=55)$ & $\mathrm{n}$ \\
\hline Epileptic seizures & $26(43.7)$ \\
Migraine & $13(23.6)$ \\
Psychogenic hyperventilation & $4(7.3)$ \\
Hypertensive encephalopathy & $2(3.6)$ \\
Transient global amnesia & $2(3.6)$ \\
Sepsis & $2(3.6)$ \\
Hypoglycaemia & $1(1.8)$ \\
Benign paroxysmal vertigo & $1(1.8)$ \\
Cerebral venous thrombosis & $1(1.8)$ \\
Neoplasm of the brain & $1(1.8)$ \\
Subarachnoid bleeding & $1(1.8)$ \\
Peripheral nerve lesion & $1(1.8)$ \\
\hline
\end{tabular}

Values in parentheses represent percentages. Diagnostic criteria for epileptic seizures according to the definitions proposed by the International League Against Epilepsy and the International Bureau for Epilepsy [39]. Diagnostic criteria for migraine with aura were those defined by the International Headache Society [40].

tween the TIA and TIA mimic groups. $A B C D(p=0.027)$ and $A B C D 2$ scores $(p=0.018)$ tended to be lower in TIA mimics compared with TIA patients.

\section{Predicting TIA Mimics versus TIA}

All 303 patients were considered for regression analysis, except for regression on blood pressure values, where 2 patients could not be considered due to missing values.

For age, symptom duration and diastolic and systolic blood pressure, no relevant nonlinear effects were detected. In the univariate linear logistic regression models (table 3), the duration of symptoms, blood pressure at admission, aphasia, dysarthria, vertigo, hemianopia, transient monocular blindness, diplopia and unilateral sensory loss did not show a statistically significant effect on the odds of TIA mimics. An increase of 5 years in age accounted for a decrease in the odds of TIA mimics of $10 \%$ [odds ratio (OR) $0.90,95 \%$ confidence interval (CI) 0.81-1.00]. Unilateral paresis accounted for a decrease in the TIA mimics odds of $71 \%$ (OR $0.29,95 \%$ CI $0.15-0.54$ ). Memory loss (OR 10.80, 95\% CI 3.66-36.07), blurred vision (OR 5.04, 95\% CI 2.14-11.87) and headache (OR 5.86, 95\% CI 2.01-17.47) were each associated with an increase in the odds of TIA mimics.

We note that transient monocular blindness $(\mathrm{n}=15)$ and diplopia $(\mathrm{n}=12)$ occurred among TIA patients but were absent among patients with TIA mimics. Therefore, the stepwise linear logistic regression model selected 4 out of 13 variables (table 4): unilateral paresis (OR 0.35, 95\% CI 0.17-0.68), headache (OR 3.71, 95\% CI 1.07-12.78), memory loss (OR 9.17, 95\% CI 2.89-32.50) and blurred vision (OR 2.48, 95\% CI 0.90-6.59).

This model resulted in a resubstitution Brier score of 0.123 and AUC of $72.8 \%$. Internally validated $0.632+$ bootstrap estimators of the Brier score and the AUC were calculated as 0.131 and $69.4 \%$, respectively. We also investigated the model selection behavior across bootstrap samples. The average number of selected variables was 6.04 (standard error 0.28). We note that unilateral paresis and memory loss were selected in all bootstrap samples, indicating that these are very stable predictors.

Finally, we included transient monocular blindness and diplopia in an exact logistic model, together with unilateral paresis, headache, memory loss and blurred vision. Owing to computer memory constraints we had to refrain from evaluating the effects of the latter variables in this model. However, we obtained a TIA mimics OR of 0.15 for transient monocular blindness (95\% CI 0-0.95) and 0.14 for diplopia (95\% CI 0-1.03), indicating that both features decrease the odds of TIA mimics once the other factors are taken into account.

\section{Outcome of Patients with TIA Mimics and TIA}

The combined outcome event (stroke, TIA, MI or death within 90 days) occurred in 36 TIA patients (14.5\%) and in none of the patients with TIA mimics (table 5). These events were 13 strokes (5.2\%), 20 recurrent TIAs (8.1\%) and 3 MIs (1.2\%). No patient died during the follow-up period. One of the strokes occurred within 30 days of carotid stenting.

\section{Discussion}

This prospective study yielded the following main results: (1) about 1 out of 5 patients with a tentative diagnosis of TIA made by an EMD physician had a TIA mimic rather than a true TIA; (2) paresis suggested TIA; (3) duration of symptoms, blood pressure values, language or speech abnormalities and sensory symptoms did not predict either entity, and (4) at 3 months, stroke, recurrent TIA, MI or death were absent in patients with TIA mimics but occurred in $14.5 \%$ of the TIA patients.

The proportion of patients with TIA mimics $(18.2 \%$, 95\% CI 14.0-23.0\%) is in the range of rates reported in studies with a similar setting (10, 24, 38 and 48.5\%) [1417]. Some of these studies reported on clinical differences 
Table 3. Patient baseline characteristics and unadjusted ORs for factors associated with TIA mimics

\begin{tabular}{|c|c|c|c|c|c|}
\hline Covariate & $\begin{array}{l}\text { All patients } \\
(\mathrm{n}=303)\end{array}$ & $\begin{array}{l}\text { TIA mimics } \\
(\mathrm{n}=55 ; 18.2 \%)\end{array}$ & $\begin{array}{l}\text { TIA } \\
(\mathrm{n}=248 ; 81.8 \%)\end{array}$ & OR & $95 \% \mathrm{CI}$ \\
\hline Age, years & $71(61.0-79.0)$ & $66(56.0-76.5)$ & $72(62.0-79.0)$ & $0.90^{1}$ & $0.81-1.00$ \\
\hline \multicolumn{6}{|l|}{ Blood pressure } \\
\hline Systolic, mm Hg & $156.0(139.0-175.0)$ & $157.0(139.5-170.5)$ & $155.5(139.0-175.8)$ & $0.99^{2}$ & $0.94-1.04$ \\
\hline Diastolic, mm Hg & 85 (77.0-96.0) & $85.0(78.5-97.5)$ & $85.5(77.0-96.0)$ & $1.01^{2}$ & $0.92-1.10$ \\
\hline Duration of symptoms, min & $30.0(10.0-180.0)$ & $60.0(15-200)$ & $30.0(10.0-180.0)$ & $1.00^{3}$ & $0.99-1.01$ \\
\hline \multicolumn{6}{|l|}{ Clinical symptoms } \\
\hline Memory loss & $15(5.0)$ & $10(18.2)$ & $5(2.0)$ & 10.80 & $3.66-36.07$ \\
\hline Unilateral paresis & $161(53.1)$ & $16(29.1)$ & $145(58.5)$ & 0.29 & $0.15-0.54$ \\
\hline Blurred vision & $25(8.2)$ & $12(21.8)$ & $13(5.2)$ & 5.04 & $2.14-11.87$ \\
\hline Headache & $15(5.0)$ & $8(14.6)$ & $7(2.8)$ & 5.86 & $2.01-17.47$ \\
\hline Dysarthria & $58(19.1)$ & $7(12.7)$ & $51(20.6)$ & 0.56 & $0.22-1.25$ \\
\hline Unilateral sensory loss & $105(34.6)$ & $20(36.4)$ & $85(34.3)$ & 1.10 & $0.59-2.00$ \\
\hline Aphasia & $65(21.4)$ & $12(21.8)$ & $53(21.4)$ & 1.03 & $0.49-2.03$ \\
\hline Vertigo & $45(14.8)$ & $8(14.6)$ & $37(14.9)$ & 0.97 & $0.40-2.13$ \\
\hline Hemianopia & $11(3.6)$ & $2(3.6)$ & $9(3.6)$ & 1.00 & $0.15-4.03$ \\
\hline Transient ocular blindness & $15(5.0)$ & $0(0.0)$ & $15(6.0)$ & $0.20^{4}$ & $0.00-1.23$ \\
\hline Diplopia & $12(4.0)$ & $0(0.0)$ & $12(4.8)$ & $0.26^{4}$ & $0.00-1.60$ \\
\hline
\end{tabular}

Values represent medians (interquartile ranges) or numbers (percentages).

${ }^{1}$ Per 5 years. ${ }^{2}$ Per $5 \mathrm{~mm} \mathrm{Hg} .{ }^{3}$ Per 10 min. ${ }^{4}$ Median unbiased estimator [27].

Table 4. Results of stepwise linear logistic regression for the odds of TIA mimics, based on 301 patients without missing values

\begin{tabular}{lll}
\hline Covariate & OR & $95 \%$ CI \\
\hline Memory loss & 9.17 & $2.89-32.50$ \\
Unilateral paresis & 0.35 & $0.17-0.68$ \\
Headache & 3.71 & $1.07-12.78$ \\
Blurred vision & 2.48 & $0.90-6.59$ \\
\hline
\end{tabular}

Table 5. Vascular outcome events

\begin{tabular}{llll}
\hline & $\begin{array}{l}\text { All patients } \\
(\mathrm{n}=303)\end{array}$ & $\begin{array}{l}\text { TIA mimics } \\
(\mathrm{n}=55 ; 18.2 \%)\end{array}$ & $\begin{array}{l}\text { TIA } \\
(\mathrm{n}=248 ; 81.8 \%)\end{array}$ \\
\hline $\begin{array}{l}\text { Outcome events, } \mathrm{n} \\
\text { Cerebrovascular events }\end{array}$ & $36(11.9)$ & 0 & $36(14.5)$ \\
$\quad$ Ischemic stroke & $13(4.3)$ & 0 & $13(5.2)$ \\
$\quad$ Recurrent TIA & $20(6.6)$ & 0 & $20(8.1)$ \\
Death & 0 & 0 & 0 \\
MI & $3(1)$ & 0 & $3(1.2)$ \\
\hline
\end{tabular}

Outcome events were assessed at 90 days. Values in parentheses represent percentages. 
between patients with TIA mimics and true TIA, such as a higher $\mathrm{ABCD}$ score or differences in the occurrence of hemiparesis, speech disturbances, a gradual symptom onset and prior history of unexplained transient neurologic attack [15-17, 33], but none of them provided a comprehensive analysis of the distribution of clinical signs within both groups.

In our study population, patients with transient unilateral paresis were more likely to have a final diagnosis of TIA. This finding mirrored a similar observation from a study comparing stroke versus stroke mimics [12]. Weakness as a TIA symptom is a known predictor of consecutive stroke and represents an important element in clinical scores used to predict stroke risk $[7,23]$. Some of the predictive capability of the ABCD2 or ABCD score may be explained by the fact that patients with low scores may in truth have a TIA mimic rather than a true TIA [15-17]. However, these scores were not developed to distinguish TIA mimics from TIA and therefore cannot be recommended to be used as a diagnostic instrument in this context [16].

Memory loss, headache and blurred vision were significantly more frequent in patients with TIA mimics than in those with true TIA. These symptoms are common in patients with epileptic seizures and migraine, which represented the most frequent disorders mimicking TIA in our population.

Blood pressure values on admission did not differ between patients with TIA mimics and TIA patients. This appears counterintuitive, as stroke patients had significantly higher blood pressure values than patients with stroke mimics [12, 17]. Hypertensive encephalopathy among patients with TIA mimics might be a theoretical explanation for this finding. However, in our study only 2 patients with TIA mimics were diagnosed with this disorder. A more likely explanation is that unlike stroke, TIA does not result in a sustained blood pressure response.

Speech and language disturbances did not differ between patients with TIA and TIA mimics in our study. This finding contrasts with acute stroke assessment tools; speech is a component of the Face Arm Speech Test [34], the Cincinnati Prehospital Stroke Scale [35] and the Recognition of Stroke in the Emergency Room scale [36]. As a possible explanation, unlike persistent aphasia, transient aphasia may be caused by transient cerebral ischemia but also by an epileptic seizure or a migraine attack $[13,37]$.

In the present study, approximately 1 out of 7 TIA patients had a subsequent vascular event within 3 months after the TIA. Recurrent TIAs (8.1\%) were more frequent than strokes (5.2\%). MIs were rare (1.2\%). Consistent with previous research, most of these events occurred in the first 30 days [38]. No vascular outcome events occurred among patients with TIA mimics. This finding might also be considered an 'ad posterior validation' of the diagnosis mimics. Our study therefore demonstrated that differentiating between disorders mimicking TIA and true TIAs is also relevant with regard to the short-term risk of vascular events; differences in management and resource allocation between patients with true TIA and TIA mimics are therefore justified.

We are aware of the following limitations. Firstly, the relatively small number of patients with TIA mimics forced us to restrict the numerous possible clinical symptoms to 15 key features. Secondly, the interobserver reliability of the diagnosis of TIA is low [20,21]. Thirdly, in order to minimize the risk of misclassification, we used an experts' consensus approach as done in previous studies on stroke mimics $[12,13]$. Fourthly, we did not consider whether the onset of symptoms was abrupt or developed within seconds. Fifthly, we did not include the results of diagnostic investigations such as neuroimaging or EEG findings in this comparative analysis, as we focused on clinical differences. A refined analysis of the clinical significance of MRI in patients with suspected TIA is in progress.

In general, our data will be helpful for the development of a diagnostic tool to distinguish between TIA and TIA mimics. Our study presents a valid first approach for the selection of features that may be indicative for distinguishing between the two entities. However, further research is needed to build a valid prediction model. The added value of transient monocular blindness and diplopia needs to be evaluated in more detail, whereas the selection of important variables and selection of the functional form for continuous variables remain key aspects of model building. Investigation of the stability of a model and internal validation to assess its predictive performance are also required. Ultimately, a model will have to be externally validated and tested for clinical implications.

In conclusion, among patients with suspected TIA in the EMD, 1 out of 5 patients had a TIA mimic. Patients with TIA mimics were approximately 6 years younger than those with true TIA. Paresis suggested TIA, while duration of the symptoms, blood pressure values, language or speech abnormalities and sensory symptoms were not shown to distinguish between the two entities. The absence of vascular events or deaths within 3 months among patients with TIA mimics indicated a favorable short-term prognosis. 


\section{Acknowledgements}

This study was supported by research grants from the Swiss Heart Foundation and the Foundation of Health and CardioNeurovascular Research, Basel, Switzerland.

Heiner C. Bucher and Juliane Schäfer are supported by unrestricted grants from Santésuisse and the Gottfried and Julia Bangerter-Rhyner Foundation.

\section{Disclosure Statement}

There are no conflicts of interest.

\section{References}

1 Coutts SB, Eliasziw M, Hill MD, Scott JN, Subramaniam S, Buchan AM, Demchuk AM: An improved scoring system for identifying patients at high early risk of stroke and functional impairment after an acute transient ischemic attack or minor stroke. Int J Stroke 2008;3:3-10.

$\checkmark 2$ Eliasziw M, Kennedy J, Hill MD, Buchan AM, Barnett HJM: Early risk of stroke after a transient ischemic attack in patients with internal carotid artery disease. CMAJ 2004; 170:1105-1109.

-3 Ois A, Gomis M, Rodríguez-Campello A, Cuadrado-Godia E, Jiménez-Conde J, PontSunyer C, Cuccurella G, Roquer J: Factors associated with a high risk of recurrence in patients with transient ischemic attack or minor stroke. Stroke 2008;39:1717-1721.

$\checkmark 4$ Kleindorfer D, Panagos P, Pancioli A, Khoury J, Kissela B, Woo D, Schneider A, Alwell K, Jauch E, Miller R, Moomaw C, Shukla R, Broderick JP: Incidence and short-term prognosis of transient ischemic attack in a population-based study. Stroke 2005;36: 720-723.

5 Purroy F, Montaner J, Molina CA, Delgado P, Ribo M, Alvarez-Sabín J: Patterns and predictors of early risk of recurrence after transient ischemic attack with respect to etiologic subtypes. Stroke 2007;38:3225-3229.

-6 Rothwell PM, Coull AJ, Silver LE, Fairhead JF, Giles MF, Lovelock CE, Redgrave JNE, Bull LM, Welch SJV, Cuthbertson FC, Binney LE, Gutnikov SA, Anslow P, Banning AP, Mant D, Mehta Z: Population-based study of event-rate, incidence, case fatality, and mortality for all acute vascular events in all arterial territories (Oxford Vascular Study). Lancet $2005 ; 366: 1773-1783$.

7 Johnston SC, Gress DR, Browner WS, Sidney $S$ : Short-term prognosis after emergency department diagnosis of TIA. JAMA 2000;284: 2901-2906.

-8 Hill MD, Yiannakoulias N, Jeerakathil T, Tu JV, Svenson LW, Schopflocher DP: The high risk of stroke immediately after transient ischemic attack: a population-based study. Neurology 2004;62:2015-2020.
Paciaroni M, Agnelli G, Bertolini A, Pezzini A, Padovani A, Caso V, Venti M, Alberti A, Palmiero RA, Cerrato P, Silvestrelli G, Lanari A, Previdi P, Corea F, Balducci A, Ferri R, Falcinelli F, Filippucci E, Chiocchi P, Grandi FC, Ferigo L, Musolino R, Bersano A Ghione I, Sacco S, Carolei A, Baldi A, Ageno W: Risk of recurrent cerebrovascular event in patients with cryptogenic stroke or transient ischemic attack and patent foramen ovale: the FORI (Foramen Ovale Registro Italiano) study. Cerebrovasc Dis 2011;31: 109-116.

10 Nakajima M, Hirano T, Naritomi H, Minematsu K: Symptom progression or fluctuation in transient ischemic attack patients predicts subsequent stroke. Cerebrovasc Dis 2010;29:221-227.

11 Dennis MS, Bamford JM, Sandercock PA Warlow CP: Incidence of transient ischemic attacks in Oxfordshire, England. Stroke 1989;20:333-339.

12 Hand PJ, Kwan J, Lindley RI, Dennis MS, Wardlaw JM: Distinguishing between stroke and mimic at the bedside: the brain attack study. Stroke 2006;37:769-775.

13 Winkler DT, Fluri F, Fuhr P, Wetzel SG, Lyrer PA, Ruegg S, Engelter ST: Thrombolysis in stroke mimics: frequency, clinical characteristics, and outcome. Stroke 2009 40:1522-1525.

14 Fallon C, Noone I, Ryan J, O'Shea D, O'Laoide $\mathrm{R}$, Crowe M: Assessment and management of transient ischaemic attack - the role of the TIA clinic. Ir J Med Sci 2006;175:24-27.

15 Josephson SA, Sidney S, Pham TN, Bernstein AL, Johnston SC: Higher ABCD2 score predicts patients most likely to have true transient ischemic attack. Stroke 2008;39:30963098.

16 Quinn TJ, Cameron AC, Dawson J, Lees KR, Walters MR: ABCD2 scores and prediction of noncerebrovascular diagnoses in an outpatient population: a case-control study. Stroke 2009;40:749-753.
17 Sheehan OC, Merwick A, Kelly LA, Hannon N, Marnane M, Kyne L, McCormack PME, Duggan J, Moore A, Moroney J, Daly L, Harris D, Horgan G, Kelly PJ: Diagnostic usefulness of the ABCD2 score to distinguish transient ischemic attack and minor ischemic stroke from noncerebrovascular events: the North Dublin TIA Study. Stroke 2009;40: 3449-3454.

18 Weisskopf F, Fluri F, Amort M, Katan M, Bingisser R, Engelter ST, Lyrer PA: Prozessanalyse des Abklärungs- und Behandlungskonzeptes für Patienten mit Transitorischer Ischämischer Attacke im Universitätsspital Basel. Schweiz Arch Neurol Psychiatr 2010; 161:166-172.

19 Easton JD, Saver JL, Albers GW, Alberts MJ, Chaturvedi S, Feldmann E, Hatsukami TS, Higashida RT, Johnston SC, Kidwell CS, Lutsep HL, Miller E, Sacco RL: Definition and evaluation of transient ischemic attack: a scientific statement for healthcare professionals from the American Heart Association/ American Stroke Association Stroke Council; Council on Cardiovascular Surgery and Anesthesia; Council on Cardiovascular Radiology and Intervention; Council on Cardiovascular Nursing; and the Interdisciplinary Council on Peripheral Vascular Disease. The American Academy of Neurology affirms the value of this statement as an educational tool for neurologists. Stroke 2009;40: 2276-2293.

20 Koudstaal PJ, Gerritsma JG, van Gijn J: Clinical disagreement on the diagnosis of transient ischemic attack: is the patient or the doctor to blame? Stroke 1989;20:300-301.

21 Kraaijeveld CL, Van Gijn J, Schouten HJ, Staal A: Interobserver agreement for the diagnosis of transient ischemic attacks. Stroke $1984 ; 15: 723-725$

22 Fluri F, Hatz F, Voss B, Lyrer PA, Engelter ST: Restenosis after carotid endarterectomy: significance of newly acquired risk factors. Eur J Neurol 2010;17:493-498.

-23 Rothwell PM, Giles MF, Flossmann E, Lovelock CE, Redgrave JNE, Warlow CP, Mehta $\mathrm{Z}$ : A simple score (ABCD) to identify individuals at high early risk of stroke after transient ischaemic attack. Lancet 2005;366:2936. 
24 Wood SN: Fast stable direct fitting and smoothness selection for generalized additive models. J R Stat Soc B 2008;70:495-518.

25 Cox DR, Snell EJ: Analysis of Binary Data. London, Chapman and Hall, 1989.

-26 Hirji KF, Mehta CR, Patel NR: Computing distributions for exact logistic regression. Am Stat Assoc 1987;82:1110-1117.

-27 Hirji KF, Tsiatis AA, Mehta CR: Median unbiased estimation for binary data. Am Stat 1989;43:7-11.

28 StataCorp: Stata Statistical Software, release 10. College Station, StataCorp, 2007.

29 Akaike H: Information theory and an extension of the maximum likelihood principle; in Petrov BN, Csádki F (eds): Second International Symposium on Information Theory, Tsahkadsor, Armenia, USSR, September 2-8, 1971. Budapest, Akadémiai Kiadó, 1973, pp 267-281.

-30 Brier GW: Verification of forecasts expressed in terms of probability. Mon Weather Rev 1950;78:1-3.
31 Efron B: Improvements on cross-validation: the 632+ bootstrap method. J Am Stat Assoc 1997;93:548-560.

32 RDCT: R: A Language and Environment for Statistical Computing. Vienna, R Foundation for Statistical Computing, 2009. http:// www.R-project.org.

-33 Prabhakaran S, Silver AJ, Warrior L, McClenathan B, Lee VH: Misdiagnosis of transient ischemic attacks in the emergency room. Cerebrovasc Dis 2008;26:630-635

34 Harbison J, Hossain O, Jenkinson D, Davis J, Louw SJ, Ford GA: Diagnostic accuracy of stroke referrals from primary care, emergency room physicians, and ambulance staff using the face arm speech test. Stroke 2003;34 71-76.

35 Kothari RU, Pancioli A, Liu T, Brott T, Broderick J: Cincinnati Prehospital Stroke Scale: reproducibility and validity. Ann Emerg Med 1999;33:373-378.
36 Nor AM, Davis J, Sen B, Shipsey D, Louw SJ, Dyker AG, Davis M, Ford GA: The Recognition of Stroke in the Emergency Room (ROSIER) scale: development and validation of a stroke recognition instrument. Lancet Neurol 2005;4:727-734.

>37 Hanlon RE, Lux WE, Dromerick AW: Global aphasia without hemiparesis: language profiles and lesion distribution. J Neurol Neurosurg Psychiatry 1999;66:365-369.

>38 Wu CM, McLaughlin K, Lorenzetti DL, Hill MD, Manns BJ, Ghali WA: Early risk of stroke after transient ischemic attack: a systematic review and meta-analysis. Arch Intern Med 2007;167:2417-2422.

-39 Fisher RS, van Emde Boas W, Blume W, Elger C, Genton P, Lee P, Engel J: Epileptic seizures and epilepsy: definitions proposed by the International League Against Epilepsy (ILAE) and the International Bureau for Epilepsy (IBE). Epilepsia 2005;46:470-472.

40 Headache Classification Subcommittee of the International Headache Society: The International Classification of Headache Disorders: 2nd edition. Cephalalgia 2004;24 (suppl 1):9-160. 